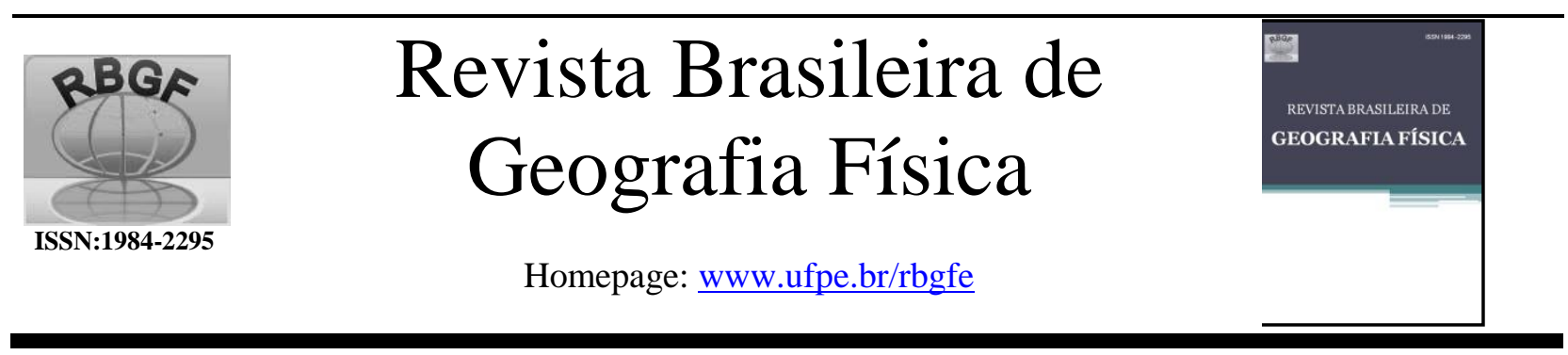

\title{
Estimativa climática sazonal da produtividade de açaí (Euterpe oleracea mart.) no Estado do Pará - cenários futuros
}

Thaiane Soeiro da Silva Dias ${ }^{1}$, Everaldo Barreiros de Souza ${ }^{2}$, Mário Augusto Gonçalves Jardim ${ }^{3}$, Paulo Jorge Oliveira Ponte de Souza ${ }^{4}$, Edson José Paulino da Rocha ${ }^{5}$, Amanda Nascimento Pinheiro ${ }^{1}$, Vânia dos Santos Franco ${ }^{1}$, Rodrigo Carréra dos Santos ${ }^{6}$, Tharine Soeiro da Silva Dias Vidal ${ }^{7}$

\begin{abstract}
${ }^{1}$ Mestres em Ciências Ambientais, Universidade Federal do Pará (UFPA), Instituto de Geociência (IG), Belém, Pará, thaiane.dias24@ gmail.com (autor correspondente); nanda_tkr18@hotmail.com, vsanfranco@yahoo.com.br. ${ }^{2}$ Professor Associado, UFPA, IG, Faculdade de Meteorologia (FAMET), Programa de pós-graduação em Ciências Ambientais (PPGCA), Belém, Pará, everaldo@ufpa.br. ${ }^{3}$ Pesquisador do Ministério da Ciência, Tecnologia, Inovações e Comunicações, Museu Paraense Emílio Goeldi (MPEG), Coordenação de Botânica, Belém, Pará; jardim @ museu-goeldi.br. ${ }^{4}$ Professor Dr. Adjunto IV, Instituto Socioambiental e dos Recursos Hídricos (ISARH), Universidade Federal Rural da Amazônia (UFRA), Belém, Pará; paulo.jorge@ufra.edu.br. ${ }^{5}$ Professor Doutor, UFPA, FAMET, PPGCA, Belém, Pará, eprocha@ufpa.br. ${ }^{6}$ Discente em Educação Física, UFPA, Belém, Pará, charlie.decker90@gmail.com. ${ }^{7}$ Matemática, Instituto Federal do Pará (IFPA), Belém, Pará, tharinevidal208@ gmail.com.
\end{abstract}

Artigo recebido em 06/09/2018 e aceito em 12/03/2019

\section{R E S U M O}

O presente trabalho considera as relações entre a sazonalidade climática regional e a produção de frutos de açaí representativa de 30 municípios do Estado do Pará durante um período de 9 anos (2003 a 2011). Os testes paramétricos de correlação de Pearson determinaram que o regime do período chuvoso (meses de Dezembro a Maio) associa-se a alta produtividade de frutos de açaí, enquanto que o período seco (Junho a Novembro) relaciona-se com baixa produtividade de frutos de açaí. Além disso, foram investigadas as estimativas climáticas na produção de frutos de açaí levando em conta os cenários futuros a partir dos resultados de um modelo de regressão linear tendo como variáveis preditoras: precipitação, temperatura e umidade atmosférica, fornecidos pelo modelo global HadGEM2 do IPCC (1979-2032), observou-se que a produtividade de frutos de açaí $(\mathrm{kg} / \mathrm{ha})$ tende sofrer mudanças significativas nos próximos 15 anos (2017 a 2032).

Palavras-chaves: climatologia, cenários futuros, sazonalidade, regressão, Euterpe oleracea Mart.

\section{Climatic seasonal estimative over the productivity of açaí (Euterpe oleracea Mart,) at State of the Pará - future scenarios}

\section{A $\quad$ B $\quad \mathbf{S} \mathbf{T} \quad \mathbf{R}$ A $\mathbf{C}$ T}

The present work considers the relationship between the regional climatic seasonality and açaí fruits production, representative of 30 cities of Pará during a period of 9 years (2003 to 2011). The Parametric tests of Pearson correlations determined such as the regime of rainy period (months of December to May) is associated to the high productivity of açaí fruits, while the regime of dry period (June to November) relates with low productivity of açaí fruits. Moreover, it was investigated the climatic estimative on production of açaí fruits taking into account the future scenarios. Through the results of a linear regression model using as predictors variables: precipitation, temperature and humidity provided by HadGEM2 global model of IPCC (1979-2032), it is observed that the productivity of açaí fruits (kg/ha) tend to suffer significative changes in the next 15 years (2017 to 2032).

Keywords: climatology, future scenarios, seasonality, regression, Euterpe oleracea Mart. 


\section{Introdução}

Nas últimas décadas as pesquisas científicas nas áreas de meteorologia, climatologia e hidrologia têm abordado diversas temáticas e metodologias de análises. Nestas pesquisas é consenso que a variável de grande importância com relação ao clima, particularmente da Amazônia, é a precipitação pluviométrica (De Souza et al., 2016). Sabe-se que o ciclo anual da precipitação apresenta seu máximo durante as estações do verão e outono austral (entre Dezembro a Maio) e seu mínimo durante o regime menos chuvoso ou seco (entre Junho a Novembro), como pautado em (De Souza et al., 2017).

A variabilidade pluviométrica por sua vez é dependente dos mecanismos de grande escala que se processam nos Oceanos tropicais adjacentes: o Pacífico e Atlântico (Souza et al., 2017). O Padrão de Dipolo caracteriza-se pela manifestação simultânea de anomalias de TSM configurando-se espacialmente com sinais opostos sobre as Bacias Norte e Sul do Atlântico Tropical. Este padrão térmico inverso gera consequentemente, o aparecimento de um gradiente térmico meridional e inter-hemisférico sobre o Atlântico Equatorial, o qual exerce influencia no deslocamento norte-sul da Zona de Convergência Intertropical (ZCIT), como demonstrado (Sodré et al.,2015; De Azevedo et al., 2017). Esses sistemas meteorológicos induzem nos maiores volumes acumulados de chuvas para as regiões Norte e Nordeste do Brasil.

Assim, áreas suscetíveis no que concerne às atividades econômicas do setor produtivo, particularmente aquelas ligadas à agricultura tendem apresentar dependência da variabilidade pluviométrica regional, como é o caso do Estado do Pará, segundo (Nogueira e De Santana, 2018). A mudança na precipitação afeta o extrativismo, desencadeando problemas de ordem social, econômicas e ambiental para uma parcela da população paraense.

$\mathrm{O}$ foco do presente trabalho é a produtividade dos frutos de açaí, que é a produção extrativista mais tradicional e importante da Amazônia. O açaizeiro (Euterpe oleracea Mart.) é nativo da Amazônia brasileira, onde o Estado do Pará é o principal centro de dispersão dessa palmácea. De acordo com a Companhia Nacional de Abastecimento - CONAB, as populações de açaizeiros também são encontradas nos Estados do Amazonas, Amapá, Maranhão, Mato Grosso e Tocantins. No entanto, é na região do estuário do rio Amazonas que se concentram as maiores e mais densas populações naturais dessa palmeira, adaptada às condições elevadas de temperatura, precipitação pluviométrica e umidade relativa do ar, conforme o autor (Freire et al., 2013).

Então, nesta perspectiva, os setores agrícolas devido a sua forte dependência ao clima, há necessidades cada vez maiores de estudos científicos, ferramentas capazes de prever ou antecipar informações para planejamentos e tomadas de decisões. Tendo em vistas as mudanças climáticas globais para meados e final do século XXI, reportadas no quarto relatório do Intergovernmental Panel on Climate Change (IPCC AR4, 2007) e no quinto relatório (IPCC AR5, 2013). As simulações obtidas em diversos modelos do sistema climático global apontam a Amazônia como uma das regiões ao redor do globo considerada como hotspot ${ }^{l}$ (Torres et al., 2012) de mudanças climáticas, cujas projeções apontam para condições mais quentes e mais secas nos próximos 50 anos (Marengo et al., 2012; PBMC, 2013).

Neste contexto, o presente trabalho também apresenta uma contribuição sobre os impactos das mudanças climáticas na produtividade de frutos de açaí em decorrência de possíveis cenários futuros de clima regional sobre a Amazônia oriental durante as próximas duas décadas.

\section{Material e métodos}

Localização da área e tipos de dados

A área de estudo foi centrada no Estado do Pará que possui referências no setor econômico como principal produção comercial do produto de açaí (Martinot et al., 2017). Nessa região, foram selecionados 30 municípios maiores produtores de frutos. Em cada município foram coletados dados da área cultivada e quantidade produzida de açaí do banco de Pesquisa Agropecuária Municipal do IBGE, dados disponíveis de 2003 a 2011 (nove anos).

O rendimento médio ou produtividade média $(\mathrm{kg} / \mathrm{ha})$ de cada município foram calculados da quantidade produzida em relação a área cultivadas de cada ano (2003 a 2011). Depois de ser calculados foi possível identificar três níveis de produtividade, definido como: região de maior produtividade (A1), região de moderada produtividade (A2) e região de menor produtividade (A3), conforme a Figura 1.

\footnotetext{
${ }^{1}$ Hotspot é usado nos estudos climáticos para designar regiões com projeções de mudanças climáticas significativas aliadas ao alto grau de vulnerabilidade socioambiental.
} 
Para caracterização climatológica sazonal foi utilizados dados mensais de precipitação PREC em $\mathrm{mm} / \mathrm{dia}$, umidade relativa - UR em porcentagem (\%), temperatura máxima - TMAX e mínima - TMIN em ${ }^{\circ} \mathrm{C}$ de cinco estações meteorológicas e pertencentes ao Instituto Nacional de Meteorologia (INMET), disponíveis do banco de dados meteorológicos para ensino e pesquisa (BDMET), para o mesmo período (2003 a 2011). A Figura 1 mostra a localização geográfica das estações que foram utilizadas no estudo (PMO - Porto de Moz, BRE - Breves, SOU - Soure, TUC- Tucuruí, CAM - Cametá), as quais se situam, justamente, sobre a região que engloba os 30 municípios produtores de frutos de açaí no Estado do Pará.

Utilizaram-se também os dados em ponto de grade de precipitação obtidos do Climate Prediction Center (CPC) fornecidos pelo PSD NOAA / OAR / ESRL, Boulder, Colorado, EUA. Estes dados foram gerados através da interpolação espacial dos dados observados nas estações meteorológicas de superfície, reportados na codificação SYNOP das 1200UTC. Além desses, foram usados dados de Radiação de Onda Longa Emergente (ROLE), estimados por satélites, que são indicativos de nebulosidade convectiva tropical, os quais se encontram disponíveis numa grade global com resolução de $2,5^{\circ}$ no período de 1979 a 2012, documentados pelos autores
Liebmann e Smith (1996).

Métodos e Procedimentos de análise

Para investigar a relação da produtividade com sazonalidade climática, o primeiro passo, foi aplicar o procedimento de regionalização, na qual se adotou região de maior produtividade (A1) localizada na mesorregião do Marajó; região de moderada produtividade (A2) localizada no Nordeste e Sudeste paraense; e região de menor produtividade (A3) localizadas nas mesorregiões do Baixo amazonas e Sudoeste do Pará (A3).

Em seguida, foram realizados os testes paramétricos de correlação entre a sazonalidade climática regional e a produtividade de açaí que engloba os três níveis de áreas (A1, A2 e A3). Para análise utilizou-se as variáveis climáticas PREC, TMÁX, TMÍN e UR para o período sazonal chuvoso (DJFMAM) e seco (JJASON), referentes aos noves anos de estudo (2003 a 2011).

O cálculo da correlação foi obtido através do produto de Pearson, dada pela equação ( $r x y$ ), conforme usado por Freire et al. (2013).

$$
\begin{gathered}
\quad r x y=\frac{\sum_{i=1}^{n}\left(x_{i}-\bar{x}\right)\left(y_{i}-\bar{y}\right)}{(n-1) s_{x} s_{y}}= \\
\frac{\sum_{i=1}^{n}\left(x_{i}-\bar{x}\right)\left(y_{i}-\bar{y}\right)}{\sqrt{\sum_{i=1}^{n}\left(x_{i}-\bar{x}\right)^{2}} \sum_{i=1}^{n}\left(y_{i}-\bar{y}\right)^{2}}
\end{gathered}
$$

Onde: $\bar{x}$ e $\bar{y}$ são as médias das amostras de $x$ (PREC, TMÁX, TMÍN e UR) e $y$ (produtividade de açaí $\mathrm{em} \mathrm{kg} / \mathrm{ha}$ ), e $s x$ e $s y$ são os desvios padrão das amostras de $x$ e $y$. 

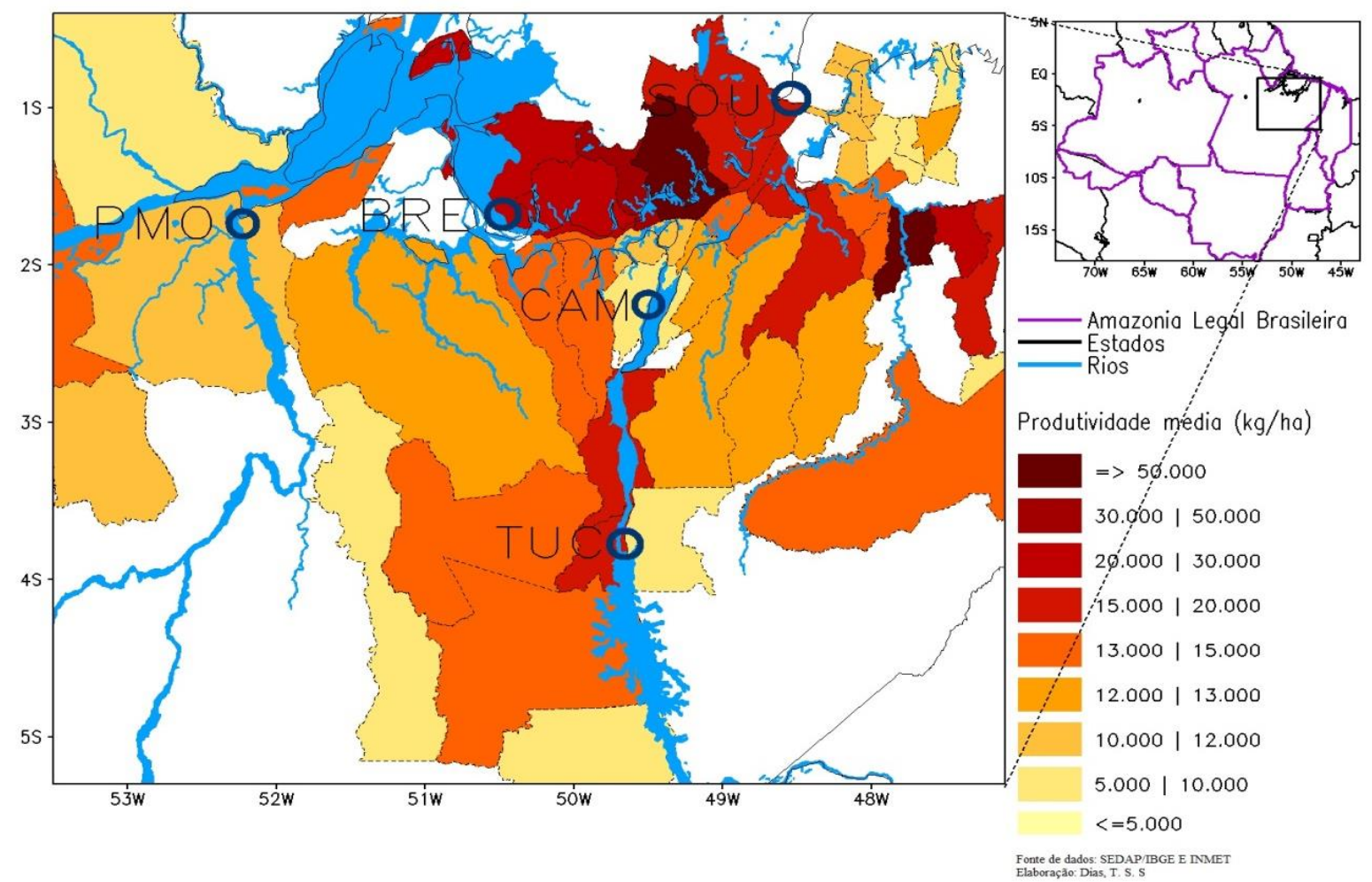

Figura 1- Localização das 5 estações meteorológicas (círculos em azul marinho) do INMET nos municípios de PMO - Porto de Moz, BRE - Breves, SOU - Soure, CAM - Cametá, TUC - Tucuruí sobre a região que engloba 30 municípios de maior produção de frutos de açaí.

A magnitude do coeficiente foram classificados seguindo-se a classificação proposta por Dancey e Reidy 2006, na qual aponta para uma classificação diversificada, em que: $r=0,10$ até 0,30 é dito (fraco); $r=0,40$ até 0,60 (moderado); $r$ $=0,70$ até 1 (forte). Quanto mais próximo de -1 ou 1 a correlação é dita perfeita. Para estabelecer a interação das condições climáticas em relação à produtividade, aplicou-se a análise de regressão (simples e múltipla). De acordo (Franco et al., 2018) o princípio consiste em modelar uma variável quantitativa dependente $y$ através da combinação linear de $p$ variáveis explicativas quantitativas $x_{1}, x_{2}, \ldots, x_{p}$.

O modelo estatístico pode ser escrito para observações $i$ como segue na equação $\left(y_{i}\right)$ abaixo:

$$
y_{i}=\beta_{0}+\sum_{j=1}^{p} \beta_{j} x_{i j}+\varepsilon_{i}
$$

Em que $y_{i}$ é o valor resposta da observação (produtividade de fruto) para a variável dependente e observação $i(a c ̧ a i)$, $x_{i j}$ é o valor considerado pela variável $j(1,2,3 \ldots)$, e observação $i$, e $\varepsilon_{i}$ é o erro do modelo, $\beta_{0 j}$ é o intercepto de cada modelo. Para o caso de regressão simples $\mathrm{p}=1 \mathrm{e}$ para o caso de regressão múltipla $p=1,2$ ou 3 ou mais, ou seja, usa-se 2 ou mais variáveis explicativas para prever $\mathrm{y}$.

Para elucidar o desenvolvimento do modelo de regressão analisaram-se dois parâmetros estatísticos, coeficiente de determinação $\left(\mathrm{R}^{2}\right) \mathrm{e} o$ Erro Percentual Médio Absoluto (MAPE).

Os aspectos de simulação do clima atual e futuro foram baseados nos resultados da versão 2 do modelo do Hadley Centre - HadGEM2 de Collins et al. 2011, que usa o estado-da-arte em simulação numérica do sistema climático global. O HadGEM2 é um modelo acoplado com a componente atmosférica possuindo resolução horizontal de $1.25^{\circ} \mathrm{em}$ latitude, e $1.875^{\circ} \mathrm{em}$ longitude, com 38 níveis verticais, e a componente oceânica tendo $1^{\circ}$ em latitude e longitude com 40 níveis verticais.

As saídas do modelo HadGEM2 foram preparadas para o Coupled Model Intercomparison Project phase5 (CMIP5, dados disponíveis em http://cmip-pcmdi.llnl.gov/cmip5; detalhes em Martin et al., 2011), para compor o quinto relatório do IPCC-AR5, publicado em setembro de 2013. No presente trabalho, documenta-se uma análise do desempenho do modelo HADGEM2 em simular o regime de precipitação do período chuvoso e seco para região delimitada $\mathrm{A} 2$, referente ao clima atual. 
Além disso, analisaram-se as projeções de clima futuro para os próximos 15 anos (2017 a 2032) baseado nas simulações do HADGEM, geradas com os cenários globais do IPCC denominado de RCP 4.5 (Representative Concentration Pathways; Van Vuuren et al., 2011). O cenário RCP 4.5 é considerado intermediário em termos da forçante radiativa global em torno de $4.5 \mathrm{~W} / \mathrm{m} 2$ ( $650 \mathrm{ppm}$ de $\mathrm{CO} 2$ equivalente) até o ano de 2100 .

\section{Resultados e discussão}

Sazonalidade climática regional

Com a finalidade de se investigar os aspectos climatológicos sazonais (média do período de 1979 a 2012), nos trimestres de DJF, MAM, JJA e SON na região de estudo, analisamse as médias sazonas de Radiação de Onda Longa Emergente - ROLE (Figura 2a), indicativo da atividade convectiva, ou seja, a formação de nuvens tropicais associadas à atuação da ZCIT na Amazônia oriental e também da ZCAS no centrosul da Amazônia) sobre o Brasil tropical e a distribuição climatológica de precipitação sobre o nordeste do Pará (Figura 2b).

Na Figura 2a nota-se no trimestre do verão (DJF), a presença de uma grande área contendo valores de ROLE abaixo de $220 \mathrm{~W} / \mathrm{m} 2$ (contornos em azul e roxo) que indicam a formação de nebulosidade tropical estendendo-se numa orientação noroeste/sudeste, desde o centro sul da Amazônia (sobre os estados do Amazonas, Rondônia e Mato Grosso), passando pelo centrooeste (Mato Grosso e Goiás) e chegando até a região sudeste (São Paulo e Minas Gerais) do Brasil. Esta região de convecção é primariamente associada ao posicionamento da ZCAS que possui maior frequência nos meses de dezembro e janeiro e explica a maior parte das chuvas intensas de verão sobre a maior parte do Brasil (Franco et al., 2018). A ZCAS também induz a ocorrência de precipitação no Pará, com valores entre 9 e 11 $\mathrm{mm} /$ dia ao longo dos municípios próximos ao rio Tocantins (Figura 2b).

Ainda em DJF, observa-se outra área contendo valores de ROLE entre 220 e $240 \mathrm{~W} / \mathrm{m} 2$ atuando sobre o Oceano Atlântico equatorial, próximo à costa nordeste da Amazônia oriental, notadamente nos estados do Amapá e Pará (Figura 2a). Essa região de convecção é relacionada à ZCIT que influencia diretamente nos volumes de chuva dos municípios localizados ao longo do litoral paraense e ilha de Marajó, com valores entre 9 e 11 $\mathrm{mm} /$ dia (Figura $2 \mathrm{~b}$ ).

Durante o outono (MAM), nota-se uma descaracterização da área de convecção associada à ZCAS e verifica-se o domínio de uma grande área contendo ROLE entre 200 e $230 \mathrm{~W} / \mathrm{m} 2$ que se estendem numa direção zonal desde o Amazonas até o Pará, incluindo o Oceano Attântico equatorial sul (Figura 2a). Esta faixa de convecção alongada zonalmente é devido à atuação da ZCIT que alcança sua posição mais austral em março. Assim, a ZCIT explica os altos índices pluviométricos no Pará, sendo que este período registra os valores máximos do ano, com volume de chuva maior do que $11 \mathrm{~mm} /$ dia nos municípios do nordeste paraense que inclui o Marajó (Figura 2b).

$\mathrm{O}$ trimestre do inverno (JJA) é caracterizado pela redução drástica na intensidade da precipitação (Figura 2b) no Pará, sobretudo na porção centro-sul do estado que passa a apresentar volume de chuva abaixo de $2 \mathrm{~mm} / \mathrm{dia}$ (em MAM era de 7 a $9 \mathrm{~mm} / \mathrm{dia}$ ). No setor mais a nordeste, que inclui o litoral e o Marajó, a precipitação oscila entre 3 a 7 mm/dia. O campo de ROLE (Figura 2a) mostra que a convecção (nebulosidade associada a valores de ROLE abaixo de $240 \mathrm{~W} / \mathrm{m} 2$ ) tropical encontra-se em latitudes ao norte da América do Sul e Atlântico norte, em virtude do deslocamento aparente do sol em direção ao hemisfério norte. A posição da convecção ao norte do continente associa-se com um ramo de ar descendente no centro-sul da Amazônia que inibe a formação de nuvens e explica a redução da chuva em JJA.

No trimestre da primavera (SON) a área de convecção da ZCIT ainda continua sobre o Atlântico norte (Figura 2a), contudo aparece uma região de atividade convectiva (ROLE abaixo de $220 \mathrm{~W} / \mathrm{m} 2$ ) sobre a Amazônia ocidental (Amazonas, Acre e Rondônia) que propicia o aumento de chuva nesta região.

Na porção oriental da Amazônia, o volume pluviométrico persiste com valores reduzidos entre 1 e $3 \mathrm{~mm} /$ dia.
${ }^{2} R C P 4.5$ é considerado um conjunto intermediário de influencia de emissões antrópicas incluindo $\mathrm{CO}_{2}, \mathrm{CH}_{4}, \mathrm{~N}_{2} \mathrm{O}$, HFCs, PFCs e $\mathrm{SF}_{6}$, mas também apresenta gases quimicamente ativos, tais como monóxido de carbono (CO) e compostos orgânicos voláteis (VOCs) de Clarke et al.(2007).

Dias, T. S. S., Souza, E. B., Jardim, M. A. G., Souza, P. J. O. P., Rocha, E. J. P., Pinheiro, A. N., Franco, V. S., Santos, R. C., Vidal, T. S. S. D. 


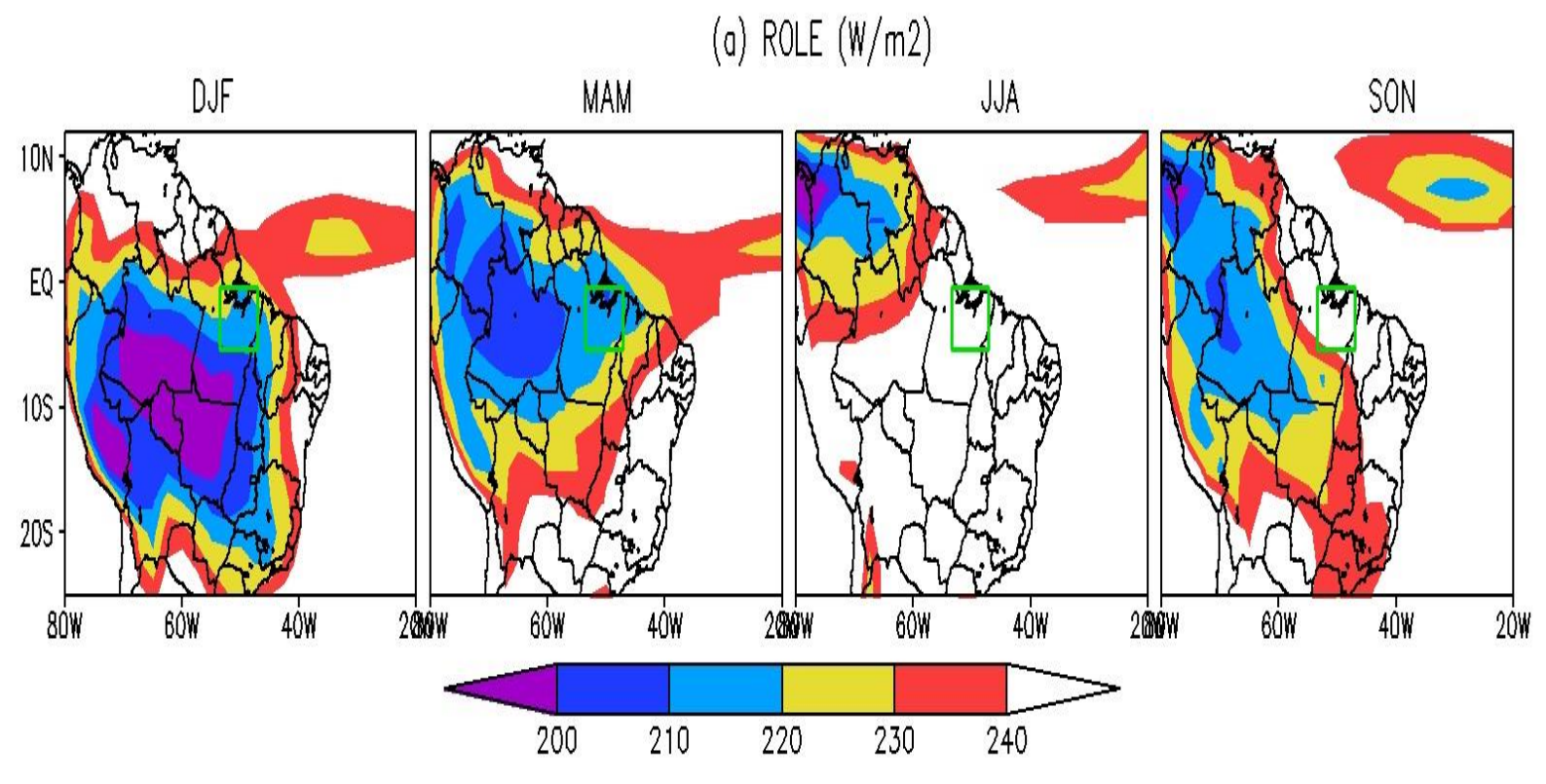

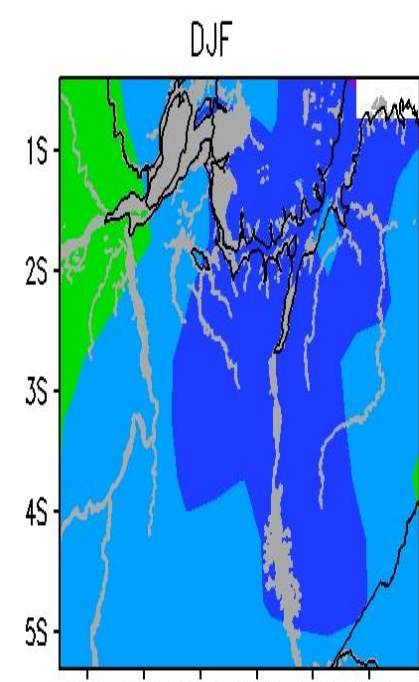

53W 52W 51W 50W 49W 48W

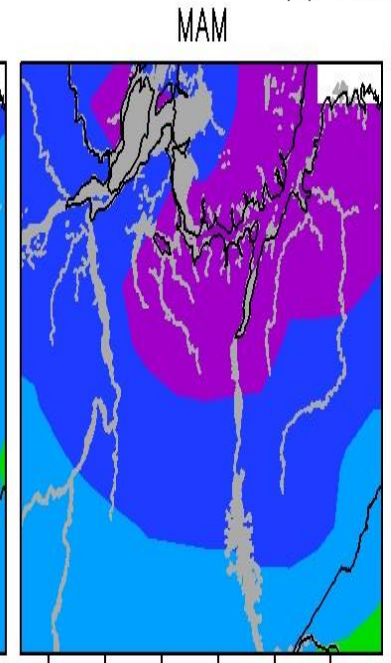

53W 52W 51W 50W 49W 48W

(b) PREC ( $\mathrm{mm} / \mathrm{dia})$

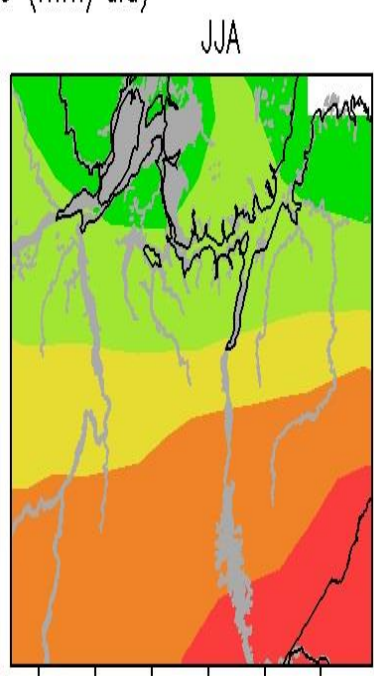

53W 52W 5IW 50W 49W 48W

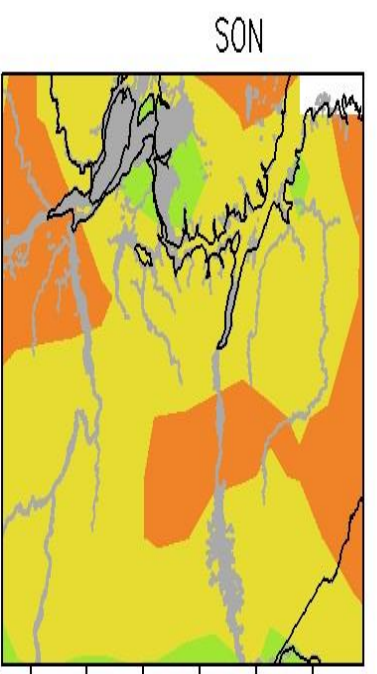

53W 52W 51W 50W 49W 48W

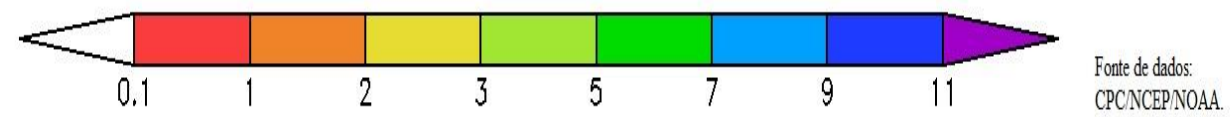

Elaboraçâa: De Souza, E. B

Figura 2 - Climatologia sazonal (média 1979/2012) de (a) ROLE sobre a América do Sul e Oceano Atlântico e (b) de precipitação - PREC sobre a região que engloba 30 municípios de maior produção de frutos de açaí, durante as estações de DJF, MAM, JJA e SON. As escalas de cores indicam a magnitude de ROLE em W/m² e de PREC em mm/dia. 
A Figura 3 destacam-se os períodos semestrais de dezembro a maio (DJFMAM) no quadrante regional (Figura 1), caracterizado pelo período tipicamente chuvoso (PREC de 11,2 $\mathrm{mm} /$ dia) com umidade alta $(86 \%)$ e temperaturas mais baixas (mínima de $24^{\circ} \mathrm{C}$ e máxima de $31,7^{\circ} \mathrm{C}$ ), enquanto que o período de junho a novembro (Jjason) é marcado pelo regime tipicamente menos chuvoso ou seco (PREC de $3 \mathrm{~mm} / \mathrm{dia}$ ) com umidade mais baixa $(79,7 \%)$ e temperaturas mais elevadas (mínima de $24,3^{\circ} \mathrm{C}$ e máxima de $33,1^{\circ} \mathrm{C}$ ).

Nesse sentindo, conclui-se que a sazonalidade climática pronunciada na região que engloba os municípios produtores de açaí, é de regime climático tipicamente chuvoso, úmido e com temperaturas do ar relativamente mais baixas no primeiro semestre, e, inversamente, de regime climático predominantemente seco com temperaturas do ar relativamente mais altas no segundo semestre. Assim sendo, tais padrões de sazonalidade interferem diretamente na fenologia de floração e frutificação, conforme reportado em Freire et al. (2013).
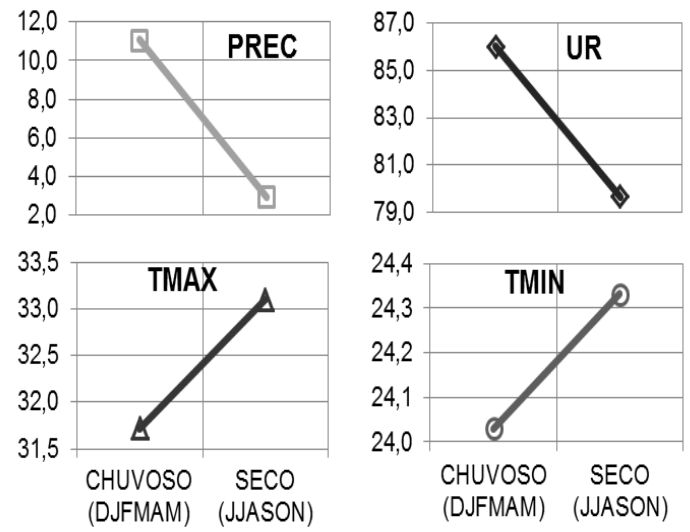

Figura 3 - Climatologia (média 1979/2012) de PREC (mm/dia), UR (\%), TMAX $\left({ }^{\circ} \mathrm{C}\right)$ e TMIN $\left({ }^{\circ} \mathrm{C}\right)$ representativa do Estado do Pará (média das 4 estações: Porto de Moz, Breves, Cametá e Soure) para os períodos chuvoso (DJfmam) e seco (Jjason).

Sazonalidade climática e a produtividade de frutos de açaí

As séries temporais das correlações de Pearson entre a série temporal da produtividade de frutos de açaí e as séries de PREC, UR, TMAX e TMIN representativos dos períodos semestrais do regime chuvoso (Djfmam) e regime seco (Jjason) durante os anos de 2003 a 2011 são mostradas na Figura $4 a$, na qual verificou-se que a produtividade de frutos de açaí vem apresentando um padrão de decrescimento continuo nos últimos nove anos.
Notou-se também que nos anos de 2003 a 2005, a variabilidade do clima regional (PREC, UR, TMAX e TMIN) apresentou um comportamento distinto para o regime seco em relação à produtividade. Esse padrão está associado à fase de El Niño que provavelmente influenciou para impactos positivos na produtividade do açaí. Segundo Souza et al. 2017, os impactos decorrentes dos anos climáticos extremos em alguns municípios podem retratar condições (favoráveis ou desfavoráveis) a produtividade de certas culturas.

A Tabela 1 mostra os valores das correlações calculadas entre as séries temporais (2003 a 2011) da produtividade de frutos de açaí (A1) e a série temporal de PREC, UR, TMAX e TMIN, (ênfase nas mesorregiões do Marajó regionalizados de SOU-BRE), para os períodos chuvoso e seco, com o respectivo valor-p e o coeficiente de determinação $\left(\mathrm{R}^{2}\right)$. Os valores encontrados para o período chuvoso foram de correlações negativas em torno de 16\% para PREC, um valor muito baixo para TMAX com $20 \%$, um pouco maior para TMIN (25\%) e UR (4\%), sendo que tais resultados não possuem significância estatística, conforme indicam o valor-p e $\mathrm{R}^{2}$. Por outro lado, os resultados para o período seco evidenciaram correlações negativas estatisticamente significantes ao nível de $90 \%$, em que o valor da TMIN foi de $71 \%$, a UR com $40 \%$, e correlação positiva, não significativa, para TMAX com valor de $2 \%$. Contudo, a correlação para a PREC é $-21 \%$.

A Tabela 2 mostra os valores para o nordeste paraense (regionalizados de CAM-TUC), percebe-se correlação negativa, para TMAX do período seco com 59\%, e correlação positiva para UR com $62 \%$, valor não significativo para TMIN (29\%) e para PREC (-5\%). Por outro lado, os resultados para o período chuvoso evidenciaram correlações negativas, não estatisticamente significantes para PREC, que apresentou valor de 45\% e para TMAX com $9 \%$. Contudo, a correlação para a TMIN é $46 \%$ e para UR é $23 \%$. A Tabela 3 têm-se os valores das correlações calculadas da mesorregião do Baixo Amazonas, para os períodos chuvoso (Djfmam) e seco (Jjason), com o respectivo valor-p e coeficiente de determinação $\left(\mathrm{R}^{2}\right)$. Os resultados encontrados para o período chuvoso foram de correlações negativas em torno de 51\% para PREC, para TMAX apresentou um valor muito baixo (7\%), para TMIN um pouco maior (-12\%) e para UR (17\%), sendo que tais resultados não possuem significância estatística, conforme indicam o valor-p e $\mathrm{R}^{2}$. Por outro lado, no período menos chuvoso é verificada 
significância para a TMIN que apresentou valor de $-53 \%$ e a UR ( $81 \%$ ) e correlação positiva, não significativa, para PREC com valor de $45 \%$. Contudo, a correlação para a TMAX foi $-35 \%$.

A interpretação física das correlações significantes indica que a diminuição/ aumento na produtividade de açaí associa-se linearmente com condições de temperaturas relativamente mais alta/baixa (tanto para TMAX como para TMIN) e umidade atmosférica relativamente mais baixa/alta (clima seco/úmido). Tais evidências são consistentes com estudos anteriores que reportaram "safras de verão" com produção mais intensa e de melhor qualidade nos meses de outubro a novembro, em base as pesquisas de Jardim e Anderson (1987), e recente confirmado (Calbo e Moraes, 2000), na qual diz que certas espécies mesófitas tem potencial osmótico tolerável ao estresse hídrico.

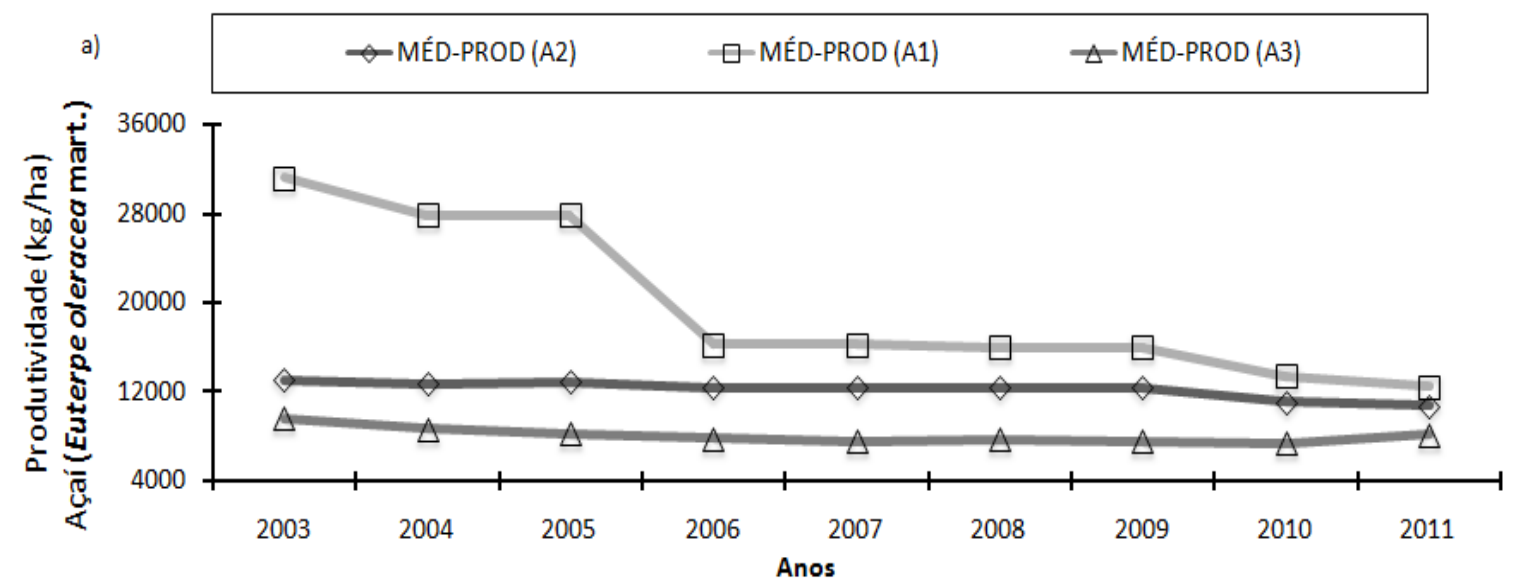

b)

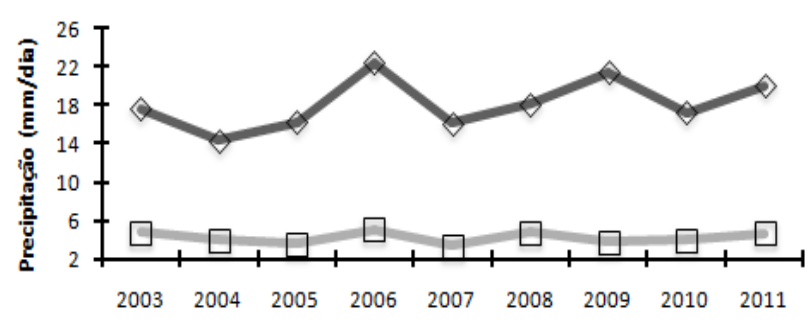

d)

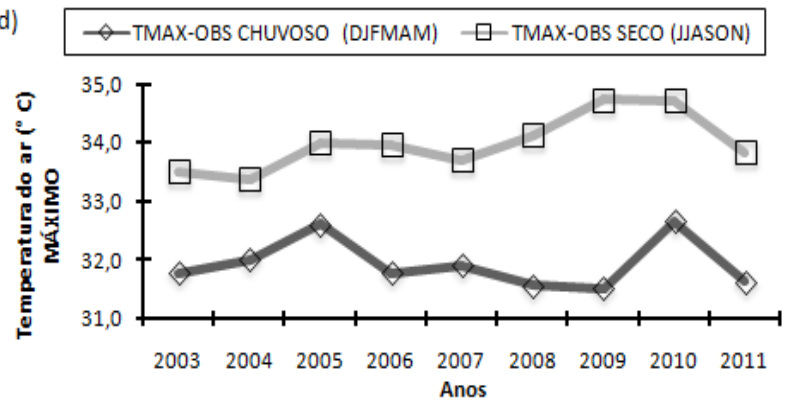

c) $\neg$ UR-OBS CHUVOSO (DJFMAM) $\square$ UR-OBS SECO (JJASON)

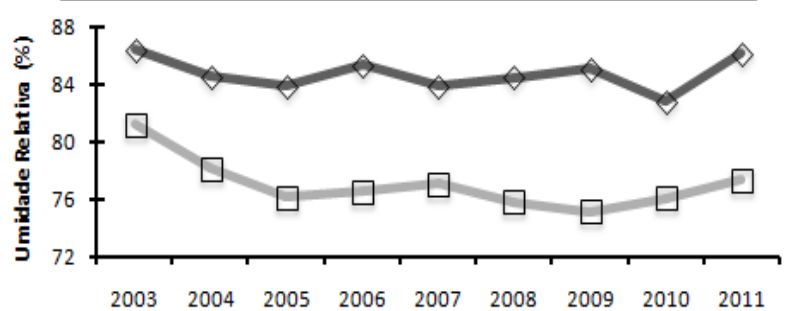

e) $\neg$ TMIN-OBS CHUVOSO (DJFMAM) $\square$ TMIN-OBS SECO (JJASON)

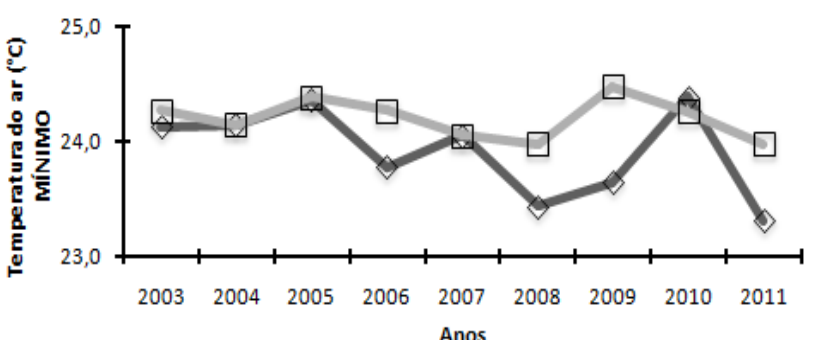

Figura 4 - Séries temporais da produtividade (em $\mathrm{kg} / \mathrm{ha}$ ) de frutos de açaí representativa do Estado do Pará (médias da produtividade que compreende A1, A2 e A3) e também da PREC (mm/dia), UR (\%), TMAX $\left({ }^{\circ} \mathrm{C}\right)$ e TMIN $\left({ }^{\circ} \mathrm{C}\right)$ da região A2(média das estações meteorológicas de PMOZ-CAM) correspondente ao período chuvoso (DJFMAM) e seco (JJASON) durante os anos de 2003 a 2011.

Tabela 1 - Correlações entre as séries temporais (2003 a 2011) da região de maior produtividade de açaí (A1) e PREC, UR, TMAX e TMIN para os períodos chuvoso (DJFMAM) e seco (JJASON), com o respectivo valor-

Dias, T. S. S., Souza, E. B., Jardim, M. A. G., Souza, P. J. O. P., Rocha, E. J. P., Pinheiro, A. N., Franco, V. S., Santos, R. C., Vidal, T. S. S. D. 
p e coeficientes de determinação (R2). Valores em negrito indicam valores significantes ao nível de 90\%.

\begin{tabular}{lccc}
\hline & Correlação: & Valor-p: & $\mathrm{R}^{2}$ : \\
\hline PREC-OBS CHUVOSO (DJFMAM) & $-0,163$ & 0,675 & 0,027 \\
TMAX-OBS CHUVOSO (DJFMAM) & $-0,202$ & 0,602 & 0,041 \\
TMIN-OBS CHUVOSO (DJFMAM) & $-0,256$ & 0,506 & 0,066 \\
UR-OBS CHUVOSO (DJFMAM) & $-0,041$ & 0,916 & 0,002 \\
PREC-OBS SECO (JJASON) & $-0,219$ & 0,571 & 0,048 \\
TMAX-OBS SECO (JJASON) & 0,025 & 0,948 & 0,001 \\
TMIN-OBS SECO (JJASON) & $\mathbf{- 0 , 7 1 0}$ & $\mathbf{0 , 0 3 2}$ & $\mathbf{0 , 5 0 5}$ \\
UR-OBS SECO (JJASON) & $\mathbf{- 0 , 4 0 6}$ & $\mathbf{0 , 2 7 9}$ & $\mathbf{0 , 1 6 5}$ \\
\hline
\end{tabular}

Tabela 2 - Correlações entre as séries temporais (2003 a 2011) da produtividade média de açaí, representantes da região A2 e PREC, UR, TMAX e TMIN para os períodos chuvoso (DJFMAM) e seco (JJASON), com o respectivo valor-p e coeficiente de determinação (R2). Valores em negrito indicam valores significantes ao nível de $90 \%$.

\begin{tabular}{lccc}
\hline & Correlação: & Valor-p: & $\mathrm{R}^{2}:$ \\
\hline PREC-OBS CHUVOSO (DJFMAM) & $\mathbf{- 0 , 4 5 4}$ & $\mathbf{0 , 2 2 0}$ & $\mathbf{0 , 2 0 6}$ \\
TMAX-OBS CHUVOSO (DJFMAM) & 0,091 & 0,816 & 0,008 \\
TMIN-OBS CHUVOSO (DJFMAM) & $\mathbf{0 , 4 6 2}$ & $\mathbf{0 , 2 1 1}$ & $\mathbf{0 , 2 1 3}$ \\
UR-OBS CHUVOSO (DJFMAM) & 0,235 & 0,543 & 0,055 \\
PREC-OBS SECO (JJASON) & $-0,051$ & 0,897 & 0,003 \\
TMAX-OBS SECO (JJASON) & $\mathbf{- 0 , 5 9 9}$ & $\mathbf{0 , 0 8 8}$ & $\mathbf{0 , 3 5 9}$ \\
TMIN-OBS SECO (JJASON) & 0,298 & 0,436 & 0,089 \\
UR-OBS SECO (JJASON) & $\mathbf{0 , 6 2 5}$ & $\mathbf{0 , 0 7 2}$ & 0,390 \\
\hline
\end{tabular}

Tabela 3 - Correlações entre as séries temporais (2003 a 2011) da região de menor produtividade de açaí (A3) e PREC, UR, TMAX e TMIN para os períodos chuvoso (DJFMAM) e seco (JJASON), com o respectivo valorp e coeficiente de determinação (R2). Valores em negrito indicam valores significantes ao nível de $90 \%$.

\begin{tabular}{lccc}
\hline & Correlação: & Valor-p: & $\mathrm{R}^{\mathbf{2}}:$ \\
\hline PREC-OBS CHUVOSO (DJFMAM) & $\mathbf{- 0 , 5 1 4}$ & $\mathbf{0 , 1 5 7}$ & $\mathbf{0 , 2 6 4}$ \\
TMAX-OBS CHUVOSO (DJFMAM) & $-0,074$ & 0,849 & 0,006 \\
TMIN-OBS CHUVOSO (DJFMAM) & $-0,126$ & 0,746 & 0,016 \\
UR-OBS CHUVOSO (DJFMAM) & 0,174 & 0,654 & 0,030 \\
PREC-OBS SECO (JJASON) & $\mathbf{0 , 4 5 1}$ & $\mathbf{0 , 2 2 3}$ & $\mathbf{0 , 2 0 3}$ \\
TMAX-OBS SECO (JJASON) & $\mathbf{- 0 , 3 5 6}$ & 0,347 & 0,127 \\
TMIN-OBS SECO (JJASON) & $\mathbf{- 0 , 5 3 9}$ & $\mathbf{0 , 1 3 5}$ & $\mathbf{0 , 2 9 0}$ \\
UR-OBS SECO (JJASON) & $\mathbf{0 , 8 1 0}$ & $\mathbf{0 , 0 0 8}$ & 0,656 \\
\hline
\end{tabular}


Clima futuro e projeções de produção de frutos de açaí.

Evidenciado que a sazonalidade climática regional interfere na produtividade dos frutos de açaí no Estado do Pará, e dispondo-se dos resultados de simulações de clima futuro, fez-se o exercício de analisar os impactos das mudanças climáticas para os próximos 15 anos. Inicialmente, mostram-se os resultados gerados pelo modelo HadGEM2 para região de moderada produtividade-A2 (Figura 5).

A Tabela 4 comprova os valores observados e simulados pelo modelo HadGEM2 para PREC, UR, TMAX e TMIN no regime chuvoso e seco considerando a média do período de 1979 a 2012. Considerando o regime chuvoso, a média de PREC observada é de 17,8 mm/dia e o modelo indica $6,7 \mathrm{~mm} / \mathrm{dia}$, com viés negativo de $11,1 \mathrm{~mm} /$ dia indicando uma subestimativa muito forte em torno de $61,5 \%$. A TMAX com média observada de $32,3^{\circ} \mathrm{C}$ e simulada de $31,6^{\circ} \mathrm{C}$ apresenta viés negativo de $3,2^{\circ} \mathrm{C}$ que representa subestimativa do modelo em $-9,7 \%$. O modelo simula a TMIN em um viés de $0,4{ }^{\circ} \mathrm{C}$, superestimando em $1,2 \%$. A UR observada é de $86 \%$ e simulada de 71,3 com viés negativo de $1,8 \%$ o que indica uma subestimativa em torno de
$-2,2 \%$. Os resultados para o regime seco mostram PREC observada de $4,4 \mathrm{~mm} /$ dia e simulada de 2 $\mathrm{mm} /$ dia com viés negativo de $-2,3 \mathrm{~mm} / \mathrm{dia}$ e subestimativa de $-52,2 \%$. A TMAX observada foi de $33,7^{\circ} \mathrm{C}$ e simulada de $30,9^{\circ} \mathrm{C}$ indicando um viés negativo de $-0,5^{\circ} \mathrm{C}$ e subestimativa de $-1,5 \%$. A TMIN observada foi de $24^{\circ} \mathrm{C}$ e a simulada de $23^{\circ} \mathrm{C}$, com viés negativo de $-0,5^{\circ} \mathrm{C}$ e subestimativa de $2 \%$. A UR observada foi $79,3 \%$ e a simulada $73,5 \%$ o que indica um viés negativo de $18,1 \%$, com subestimativa de $-23 \%$.

Em seguida procedeu-se a correção das séries de PREC, UR, TMAX e TMIN simuladas pelo HADGEM2 considerando os valores do viés mostrados na Tabela 4. Esse procedimento é ilustrado na Figura 5 que mostra os dados de PREC observados nos regimes chuvoso e seco e os valores simulados pelo modelo HadGEM2, incluindo o resultado original (valor bruto) do modelo e a correção feita pelo respectivo viés em $\mathrm{mm} /$ dia para cada série. Tal procedimento também foi empregado para as outras variáveis de clima regional das mesorregiões A1 e A3, UR, TMAX e TMIN.
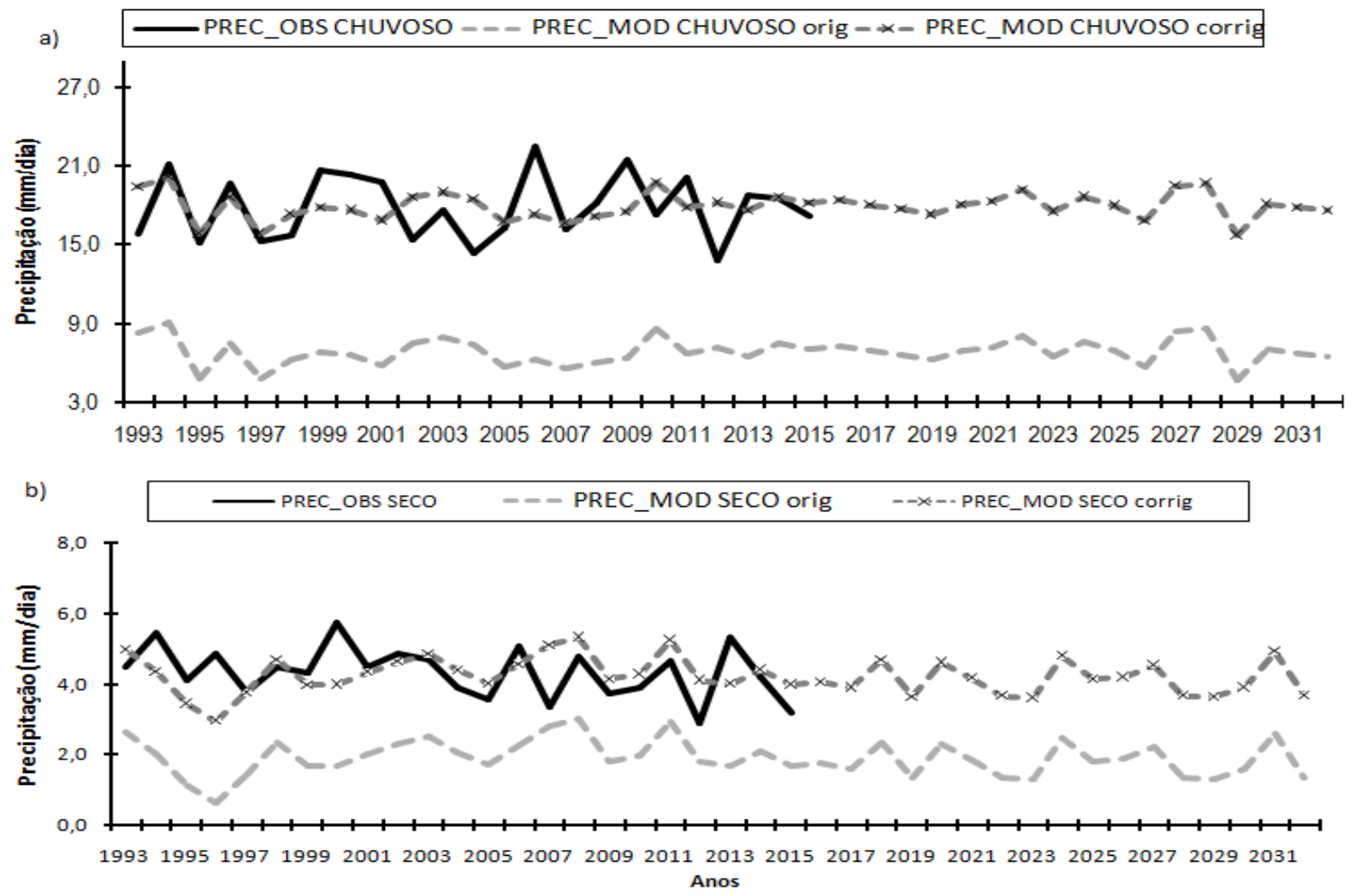

Figura 5 - Séries temporais da PREC ( $\mathrm{mm} / \mathrm{dia}$ ) observada nos regimes chuvoso e seco e os valores simulados pelo modelo HadGEM2 incluindo o resultado original (valor bruto) do modelo e a correção feita pelo respectivo valor de intensidade e sinal do viés em mm/dia, da região (A2), periodo1993 a 2032. 
Tabela 4 - Valores observados e simulados pelo HADGEM2 de PREC (mm/dia), UR (\%), TMAX $\left({ }^{\circ} \mathrm{C}\right)$ e TMIN $\left({ }^{\circ} \mathrm{C}\right)$ na região da $\mathrm{A} 2$ para o regime chuvoso e seco considerando o o clima atual (1979/2012) incluindo o viés do modelo em $\mathrm{mm} /$ dia e em $\%$

\begin{tabular}{lcccc}
\hline & OBSERVADO & HADGEM2 & $\mathrm{v}$ & \multirow{2}{*}{$\%$} \\
\hline PREC CHUVOSO & $1979 / 2012$ & $1979 / 2012$ & $\mathrm{~mm} / \mathrm{dia}$ & $\mathrm{v}$ \\
TMAX CHUVOSO & 32,3 & 6,7 & $-11,1$ & $-61,5$ \\
TMIN CHUVOSO & 23,6 & 23,9 & $-3,2$ & $-9,7$ \\
UR CHUVOSO & 86,0 & 71,3 & $-1,8$ & $-2,2$ \\
PREC SECO & 4,4 & 2,0 & $-2,3$ & $-52,2$ \\
TMAX SECO & 33,7 & 30,9 & 0,5 & 1,5 \\
TMIN SECO & 24,0 & 23,0 & 0,5 & 2,0 \\
UR SECO & 79,3 & 73,5 & $-18,1$ & $-23,0$ \\
& & & & \\
\hline
\end{tabular}

Após a aplicação do procedimento de correção dos valores simulados pelo modelo HadGEM2, foram, novamente, calculadas as médias do período 1979 a 2012 e, como esperado, os resultados da Tabela 5 mostram consistência com as médias reportadas na Tabela 4 para os dados observacionais.

Também foram calculadas as médias de clima futuro do período de 2017 a 2032 (próximos 15 anos), bem como foi feita a análise de mudança percentual do clima futuro em relação ao clima atual. Os resultados na Tabela 5 indicam que para o regime chuvoso, esperam-se aumento da PREC em torno de $+1,1 \%$, diminuição de TMAX em torno de $5,5 \%$ e na UR de $14,1 \%$ e uma diminuição fraca de TMIN de $0,8 \%$. Por outro lado, para o regime seco, o modelo indica diminuição de PREC, em torno de 5,7\%, aumento de TMAX $(+7,7 \%)$ e TMIN $(+5,2 \%)$ e diminuição de UR em torno de $10 \%$, são os mesmo valores observados por Cândido et al. (2007), Yin et al. (2013), De Souza et al. (2016).

Portanto, para os meses do período chuvoso (DJFMAM) as projeções mostram um regime relativamente mais chuvoso e menos quente (TMAX), enquanto que para os meses do período seco (JJASON), as projeções são de regime mais seco e mais quente, uma vez conhecendo os erros e aplicados os procedimentos de correção das simulações, considerando os dados observacionais, é possível agora montar um modelo de regressão múltipla para gerar projeções da produtividade de açaí nos próximos 15 anos (2017-2032) usando como variáveis preditoras a PREC, UR, TMIN e observacionais, conforme as equações na Tabela 7.
TMAX do regime chuvoso e seco para os três níveis de produtividade (A1, A2 e A3).

Assim sendo, a montagem do modelo obedeceu aos seguintes passos:

- Foi construída a equação do modelo de regressão múltipla usando os dados observados de PREC e TMAX do período chuvoso, as quais apresentaram correlações não significativas, sendo que o maior valor foi $30 \%$, utilizada para o modelo do regime chuvoso;

- Similarmente, foi construída a equação, do modelo do regime seco, de regressão múltipla usando os dados observados de UR, TMAX e TMIN do período seco, nos quais se evidenciaram correlações estatisticamente significantes em torno de $60 \%$;

- Finalmente, montou-se a equação de regressão levando-se em conta as variáveis mencionadas acima para ambos os períodos chuvoso, seco e regime chuvoso-seco.

- Ressalta-se que os três modelos acima foram construídos considerando os dados observados de 2003 a 2011 (9 anos) quando dispõe-se dos dados de produtividade de açaí ( $\mathrm{kg} / \mathrm{ha}$ ) nas regiões do Estado do Pará.

- As equações dos modelos foram aplicadas usando os resultados corrigidos do modelo HadGEM2 para a geração de projeções de produção de açaí para os próximos 15 anos (2017 a 2032). A justificativa de poder usar as equações montadas com dados observacionais é que as simulações foram calibradas (corrigidas) levando-se em conta justamente o sinal do viés relativo aos dados 
A Tabelas 6 mostra os parâmetros estatísticos correspondentes a montagem dos 3 modelos, os resultados mostram que o modelo chuvoso+seco apresenta o melhor padrão, destaque para região A3, cujo R2 foi de (99\%) e erro MAPE foi de $(0,7)$.

A Figura 6 mostra os resultados da aplicação dos modelos de regressão múltipla considerando as variáveis preditoras dos períodos chuvoso, seco e chuvoso+seco. Em virtude das baixas correlações entre as condições de clima regional do período chuvoso (Tabela 1), considerando as maiores produtividade de frutos de açaí, das mesorregiões do Marajó (região A1), verifica-se que os valores das projeções são totalmente consistentes com o observado. Por outro lado, os resultados obtidos com os modelos considerando as variáveis do período seco e também do modelo considerando as variáveis do período chuvoso+seco, observam-se estimativas oscilando entre decaimento e subida de produtividade de frutos de açaí no período de 2017 a 2032. Os valores previstos apontam para um aumento da produtividade de frutos com oscilações máximas em torno de $81.300(\mathrm{~kg} / \mathrm{ha})$ e mínimas em torno de $5.519(\mathrm{~kg} / \mathrm{ha})$, ou seja, as projeções futuras, levando em conta o modelo Chuvoso + Seco, são animadoras em termos de produtividades, pois estas podem atingir níveis elevados de produtividade nas regiões do A1 nos próximos 15 anos.

Tabela 5 - Valores corrigidos do HADGEM2 de PREC (mm/dia), UR $(\%)$, TMAX $\left({ }^{\circ} \mathrm{C}\right)$ e TMIN $\left({ }^{\circ} \mathrm{C}\right)$ no nordeste paraense para o regime chuvoso e seco, considerando o clima atual (1979/2012) e clima futuro (2013/2032) o sinal de mudança em \%, no futuro relativo ao atual.

\begin{tabular}{lccc}
\hline & $\begin{array}{c}\text { HADGEM2 Corr } \\
1979 / 2012\end{array}$ & $\begin{array}{c}\text { HADGEM2 Corr } \\
2017 / 2032\end{array}$ & $\begin{array}{c}\text { Mudança \% } \\
(2017 / 2032- \\
1979 / 2012)\end{array}$ \\
\hline PREC CHUVOSO & 17,8 & 18,0 & 1,1 \\
TMAX CHUVOSO & 32,3 & 30,6 & $-5,5$ \\
TMIN CHUVOSO & 23,6 & 23,4 & $-0,8$ \\
UR CHUVOSO & 86,6 & 98,9 & 14,1 \\
PREC SECO & 4,4 & 4,1 & $-5,7$ \\
TMAX SECO & 33,7 & 36,3 & 7,7 \\
TMIN SECO & 24,0 & 25,2 & 5,1 \\
UR SECO & 80,1 & 72,1 & $-10,0$ \\
\hline
\end{tabular}

Tabela 6 - Parâmetros estatísticos correspondentes a montagem dos 3 modelos.

\begin{tabular}{ccccc} 
Área & Parâmetros & Modelo chuvoso & Modelo seco & $\begin{array}{c}\text { Modelo } \\
\text { chuvoso+seco }\end{array}$ \\
\hline A1 & $\mathrm{R}^{2}$ & 0,140 & 0,810 & 0,869 \\
& MAPE & 28,972 & 12,581 & 12,171 \\
A2 & $\mathrm{R}^{2}$ & 0,260 & 0,562 & 0,703 \\
& MAPE & 4,168 & 3,074 & 2,758 \\
A3 & $\mathrm{R}^{2}$ & 0,264 & 0,673 & 0,990 \\
& MAPE & 6,156 & 4,301 & 0,719 \\
\hline
\end{tabular}




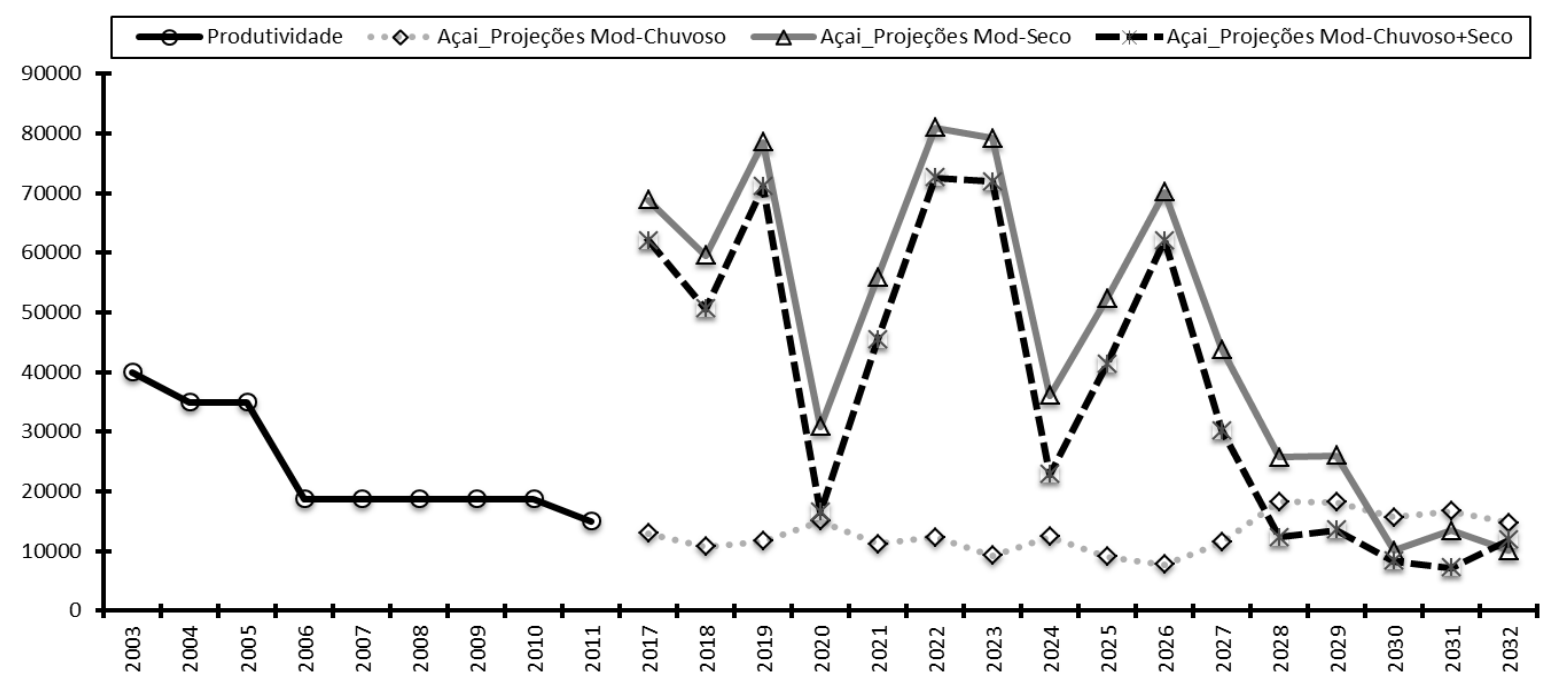

Figura 6 - Produtividade (em kg/ha) de frutos de açaí, representativos de áreas de maior produção (A1), considerando os dados observados (linha preta) e projeções para os próximos 15 anos (2017 a 2032) via regressão linear múltipla, usando PREC, UR, TMAX e TMIN simuladas pelo modelo HadGEM2 para o regime chuvoso (linha pontilhada), regime seco (linha solida-cinza) e regimes chuvoso-seco (linha tracejada).

A Figura 7, têm-se as projeções futuras para a região $\mathrm{A} 2$, conforme, considerando as variáveis preditoras do período chuvoso, do período seco e do período chuvoso + seco, nota-se que em condições de clima regional do período chuvoso, verificam-se valores de projeção de maiores produtividades, cujas correlações foram maiores a $45 \%$ em relação ao observado. Por outro lado, os resultados obtidos com os modelos considerando as variáveis do período seco e do período chuvoso + seco, observam-se valores das projeções de produtividade em concordância com os dados registrados no período de 2003 a 2011, através da análise do coeficiente de determinação $\left(\mathrm{R}^{2}=0,56\right.$ e 0,70 , respectivamente). Os valores previstos apontam para uma máxima de produtividade de frutos em torno de $18.840(\mathrm{~kg} / \mathrm{ha})$ e mínimo de 11.524 (kg/ha) nos próximos 15 anos.

E na Figura 8, em virtude das correlações serem maiores entre as condições de clima regional do período chuvoso, considerando os níveis de produtividade mínima, extrativo de frutos de açaí, nas mesorregiões do Baixo Amazônico e porção Sudoeste paraense, verifica-se similaridades dos valores das projeções com o observado. Por outro lado, os resultados obtidos com os modelos considerando as variáveis do período seco, apontam para condições desfavoráveis as produtividades nos próximos 15 anos. No modelo que considera as variáveis do período chuvoso + seco, observa-se que os valores das projeções de produtividade de açaí apresentam estimativas elevadas em relação os dados registrados no período de 2003 a 2011. Desta forma, os valores previstos apontam para um aumento da produtividade de frutos com oscilações máximas em torno de $23.300(\mathrm{~kg} / \mathrm{ha})$ e mínima de 4.485 $(\mathrm{kg} / \mathrm{ha})$ na regiões da área A3.

De acordo com Vivian Zeidemann et al. 2015, no estudo das percepções das mudanças climáticas por moradores no estuário amazônico sobre a produção do açaí, indicou que em anos climático extremos de seca, ou seja, quando um ano é mais quente que os anos normais, é percebido pelos moradores o decaimento da qualidade dos frutos e com isso, perdas de produção do frutos e prejuízos sócias e econômicos são respostas para riscos climáticas nos anos atuais.

Conclui-se que, diante dos cenários de clima futuro (2017/2032) apontam para um regime mais seco e mais quente do que as condições atuais (1979/2012), há indícios de impactos positivos e negativos na produtividade de frutos de açaí para as regiões citadas nos próximos 15 anos. Porém, destaca-se a região do Baixo Amazonas e Sudoeste do Pará (A3) como risco climático para o dessecamento da produção do açaí, onde as projeções futuras do modelo seco (Figura 8) resultam em descenso à produtividade.

Tabela 7 - Equações dos modelos representativos do nível de produtividade de açaí (A1, A2 e A3 ) para os regimes chuvoso, seco e chuvoso-seco. 


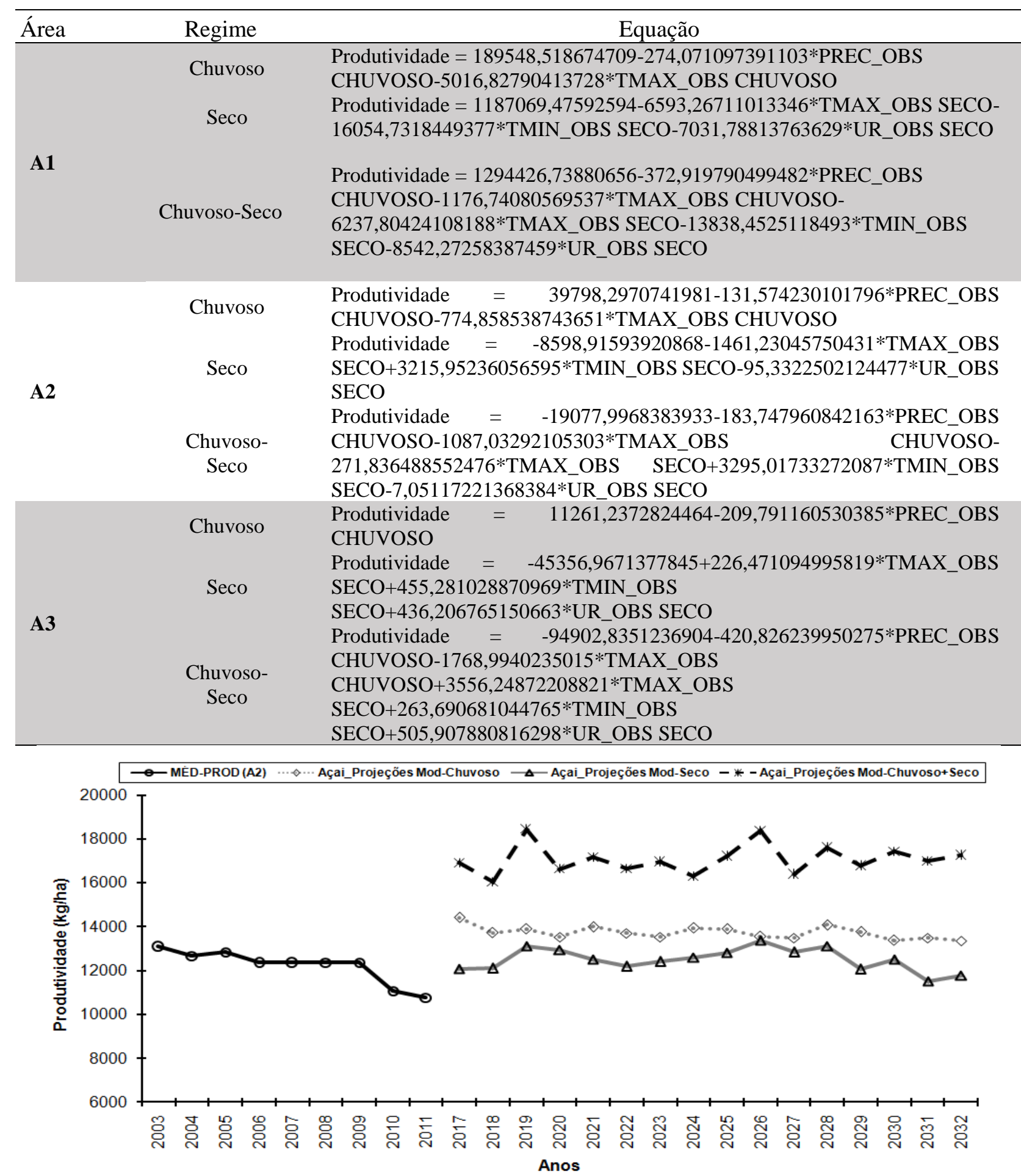

Figura 7 - Produtividade (em $\mathrm{kg} / \mathrm{ha}$ ) de frutos de açaí, representativos de áreas de produção média (A2),considerando os dados observados (linha preta) e projeções para os próximos 15 anos (2017 a 2032) via regressão linear múltipla usando PREC, UR, TMAX e TMIN simuladas pelo modelo HadGEM2 para o regime chuvoso (linha pontilhada), regime seco (linha solida-cinza) e regimes chuvoso-seco (linha tracejada). 


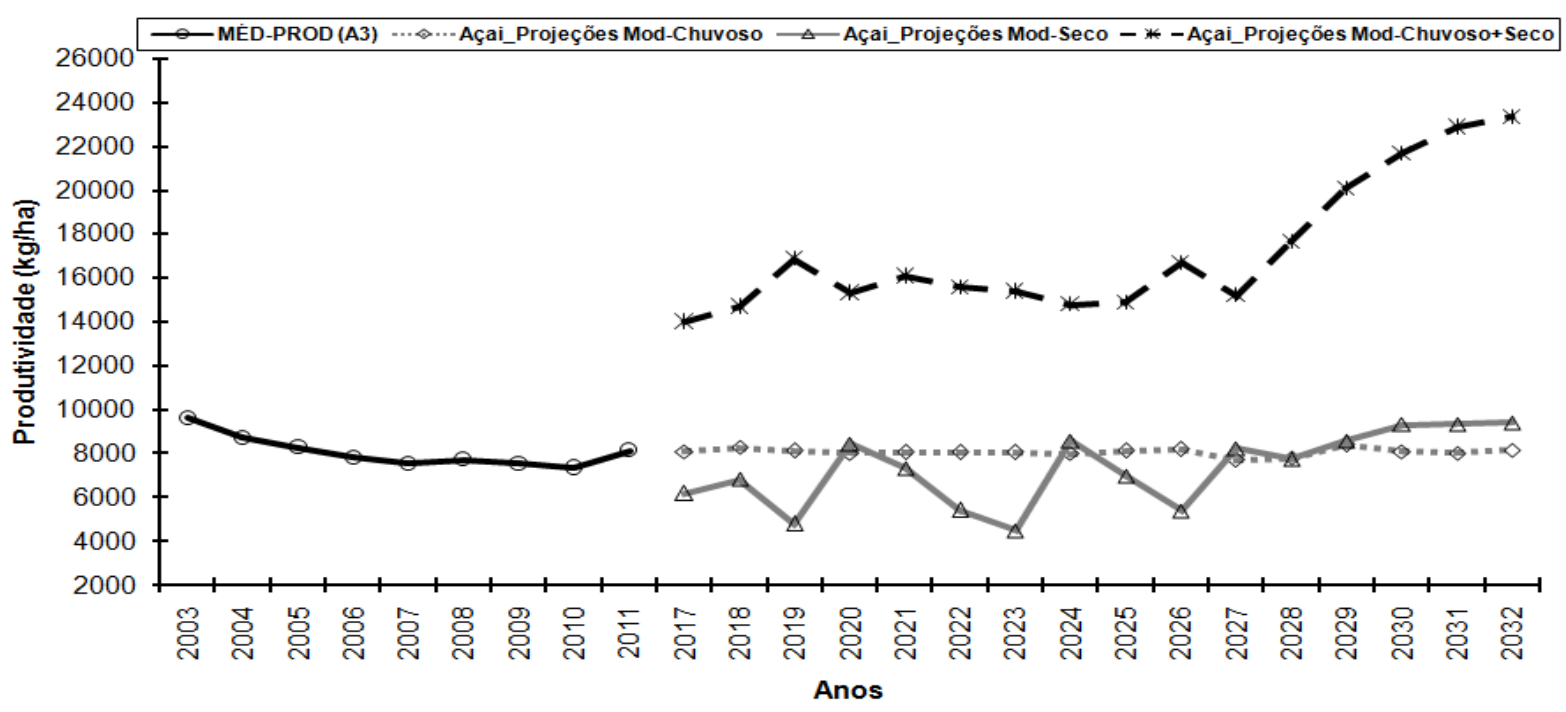

Figura 8- Produtividade (em kg/ha) de frutos de açaí, representativos de áreas de menor produção (A3), considerando os dados observados (linha preta) e projeções para os próximos 15 anos (2017 a 2032) via regressão linear múltipla usando PREC, UR, TMAX e TMIN simuladas pelo modelo HadGEM2 para o regime chuvoso (linha pontilhada), regime seco (linha solida-cinza) e regimes chuvoso-seco (linha tracejada).

\section{Conclusões}

De acordo com os dados do modelo climático HadGEM2 para o cenário RCP 4.5 do IPCC em representar a sazonalidade climática regional no Pará apresentou concordâncias com o critério regional. Assim, foi possível desenvolver um modelo empírico para estimar a produtividade de frutos de açaí sobre o estuário do rio amazônico usando como variáveis preditoras os dados de clima futuro fornecido pelo modelo HadGEM2.

O comportamento da precipitação, temperatura do ar e umidade relativa do ar para os próximos 15 anos (2017 a 2032) resultam na alta e baixa produtividade de frutos de açaí nas regiões estudadas, ou seja, os impactos decorrentes das mudanças climáticas são alarmantes para a região do Pará que concerne ao agroecossistema de plantas nativas de açaí.

Os resultados de correlações não se mostraram plenamente satisfatórios para os modelos prognósticos propostos, pois é evidente que, além dos elementos climáticos, outros fatores podem afetar a produtividade de açaí, como a limitação territorial, o tipo de trato de manejo adotadas das novas tecnologias, renda e trabalho envolvendo segurança alimentar.

Deve-se salientar que os modelos propostos não levaram em consideração essas situações adversas e, logicamente, não é adequada para se fazer uma previsão. Contudo, é possível antecipar as informações climáticas para planejamento e tomada de decisão ao benefício da sociedade, no processo de mitigação e de adaptação às mudanças climáticas na agricultura.

\section{Agradecimentos}

À Deus, segundo à UFPA, ao PPGCA, aos Professores e Pesquisadores pelas discussões científicas que muito contribuíram para as ideias iniciais desta pesquisa, às fonte de dados (INMET, IBGE, Climate Prediction Center, CMIP5), à CNPq pela bolsa de ensino, à FAMET pela infraestrutura computacional e à minha família.

\section{Referências}

Calbo, M. E. R.; Moraes, J. A. P. V. de, 2000. Efeito da deficiência de água em plantas de Euterpe oleracea (açaí). Revista Brasileira de Botânica 23, 225-230.

Cândido, L. A., Manzi, A. O., Tota, J., Silva, P. R. T. D., Silva, F. S. M. D., Santos, R. M. N. D., \& Correia, F. W. S. 2007. O Clima atual e futuro da Amazônia nos cenários do IPCC: A questão da savanização. Ciência e Cultura 59, 44-47.

Clarke, L.; Edmonds, J.; Jacoby, H.; Pitcher, H.; Reilly, J.; Richels, R., 2007. CCSP Synthesis and Assessment Product 2.1, Part A: Scenarios of Greenhouse Gas Emissions and Atmospheric Concentrations. Washington, Dc: U.S. Government Printing Office. 
Collins, W. J.; Bellouin, N.; Doutriaux-Boucher, M.; Co-Authors. 2011. Development And Evaluation Of An Earth System ModelHadgem2.Geosci Model Dev Discuss.4, 9971062.

CONAB. Companhia Nacional de Abastecimento . Conjuntura Mensal. Período 01 A 30/11/2002. Disponível:

<Http://Www.Conab.Gov.Br/Conteudos.Php? $\mathrm{A}=526 \&$ Ordem=Titulo $>$. Acesso: 15/02/2013.

CPC. Climate Prediction Center. Dados de Precipitação Globalmente Baseada em Calibre Unificado.

Disponível: https://www.esrl.noaa.gov/psd/data/gridded/da ta.cpc.globalprecip.html. Acesso:15/02/2013.

Dancey, C.; Reidy, J., 2006. Estatística sem matemática para psicologia: usando SPSS para Windows, Ed. Artmed, Porto Alegre.

De Azevedo, F. T. M., de Souza, E. B., dos Santos Franco, V., \& de Souza Souza, P. F. 2017. Prognóstico Sazonal de Precipitação Regionalizada na Amazônia Oriental. Revista Brasileira de Geografia Física [online]. Disponível https://doi.org/10.26848/rbgf.v.10.5.p15201534. Acesso: 23/07/2018.

De Souza, E. B., Carmo, A. M. C., Moares, B. C., Nacif, A., da Silva Ferreira, D. B., Rocha, E. J. P., Souza, P. J. D. O. P. 2016. Sazonalidade da precipitação sobre a amazônia legal brasileira: clima atual e projeções futuras usando o modelo regcm4 (seasonal precipitation over the brazilian legal amazon: climate current and future projections using regcm4 model). Revista Brasileira de Climatologia [online]. Disponível:

http://dx.doi.org/10.5380/abclima.v18i0.4371 . Acesso:23/07/2018.

De Souza, E. B., Da Silva Ferreira, D. B., Guimarães, J. T. F., Dos Santos Franco, V., De Azevedo, F. T. M., De Moraes, B. C. 2017. Padrões climatológicos e tendências da precipitação nos regimes chuvoso e seco da Amazônia oriental. Revista Brasileira de Climatologia [online]. Disponível: http://dx.doi.org/10.5380/abclima.v21i0.4123. Acesso:23/07/2018.

Franco, V. S.; Souza, E. B. ; Lima, A. M. M. ; Souza, A. L. ; Pinheiro, A. N. ; Dias, T. S. S. ; Azevedo, F. T. M. 2018. Previsão hidrológica de cheia sazonal do rio xingu,altamira-pa. Revista Brasileira de Climatologia [online]. Diponível:

http://dx.doi.org/10.5380/abclima.v22i0.46393 . Acesso:23/07/2018.
Freire, A. S. C.; Vitorino, M. I.; Jardim, M. A.; De Sousa, A. M. L.; Quaresma, A. C.; Oliveira, F. G.; Pereira, R. N., 2013. Analysis of the establishment of seedlings of açaí (Euterpe Oleracea Mart.) In the understory of a forest of amazon floodplain. Earth Interactions 17, 1-11.

IBGE. Instituto Brasileiro de Geografia e Estatística. Levantamento Sistemático da Produção Agrícola. Disponível:<Http://Www.Ibge.Gov.Br/Home/ Estatistica/Indicadores/Agropecuaria/Lspa/De faulttab.Shtm>. Acesso: 12/04/2013.

INMET. Instituto Nacional De Meteorologia. Banco de Dados Meteorológicos para Ensino e Pesquisa. Diponível: < Http://Www.Inmet.Gov.Br $>$.Acesso: $12 / 04 / 2013$.

IPCC AR4. Intergovernmental Panel On Climate Change. Climate Change. 2007. Synthesis Report. Contribution Of Working Groups I, Ii And Iii To The Fouth Assessment Report Of Intergovernmental Panel On Climate Change. Disponível:

https://www.ipcc.ch/publications_and_data/pu blications_ipcc_fourth_assessment_report_wg 2_report_impacts_adaptation_and_vulnerabilit y.htm. Acesso: 13/02/2015

IPCC AR5. Intergovernmental Panel On Climate Change. Climate Change 2013: The Physical Science Basis. Contribution Of Working Group I To The Fifth Assessment Report Of The Intergovernmental Panel On Climate Change. Disponível:

https://www.ipcc.ch/publications_and_data/pu blications_and_data_reports.shtml. Acesso: $13 / 02 / 2015$

Jardim, M. A. G., Anderson, A. B. , 1987. Manejo de Populações Nativas do Açaizeiro (Euterpe Oleracea Mart.) No estuário Amazônico: Resultados Preliminares. Boletim de Pesquisa Florestal, 15, 1 -19.

Liebmann, B.; Smith, C. A. 1996. Description of a complete (interpolated) outgoing longwave radiation dataset. BULL. Amer. Review, 122, 1275-1277.

Marengo, J. A.; Tomasella, J.; Soares, W. R.; Alves, L. M.; Nobre, C. A., 2012. Extreme Climatic Events In The Amazon BasinClimatological And Hydrological Context Of Recent Floods. Theoretical Applied Climatology, 107, 3-85.

Martin, G. M.; Bellouin, N; Collins, W. J.; Culverwell, I. D.; Halloran, P. R. ; Hardiman1, S. C.;Hinton, T. J.; Jones, C. D.;Mcdonald, R. E.; Mclaren, A. J.; O'connor, F. M.; Roberts, M. J.; Rodriguez, J. M.; Woodward, S.; Best, 
M. J.; Brooks, M. E.; Brown, A. R.; Butchart, N.; Dearden, C.; Derbyshire, S. H.; Dharssi, I.; Doutriaux Boucher, M.; Edwards, J. M.; Falloon, P. D.; Gedney, N.; Gray, L. J.; Hewitt, H. T.; Hobson, M.; Huddleston, M. R.; Hughes, J. ; Ineson, S.; Ingram, W. J.; James, P. M.; Johns, T. C. ; Johnson, C. E.; Jones, A.; Jones, C. P.; Joshi, M. M.; Keen, A. B.; Liddicoat, S.; Lock, A. P.; Maidens, A. V.; Manners, J. C.; Milton, S. F.; Rae, J. G. L; Ridley, J. K.; Sellar, A.; Senior, C. A.; Totterdell, I. J.; Verhoef, A.; Vidale, P. L.; Wiltshire, A., 2011. The Hadgem 2 family of met office unified model climate configurations. Geosci. Model development 4, 723-757.

Martinot, J. F., Pereira, H. D. S., \& Silva, S. C. P. D. 2017. Coletar ou Cultivar: as escolhas dos produtores de açaí-da-mata (Euterpe precatoria) do Amazonas. Revista de Economia e Sociologia Rural 55, 751-766.

Nogueira, A. K. M.; De Santana, A. C. 2018. Influência das chuvas na oferta de Castanhado-Brasil e o impacto no benefício socioeconômico e ambiental, no Oeste do estado do Pará. Desenvolvimento E Meio Ambiente [online]. Disponível: http://dx.doi.org/10.5380/dma.v45i0.50562 . Acesso: 23/07/2018.

PBMC. Painel Brasileiro de Mudanças Climaticas. 2013. Contribuição do grupo de trabalho I ao primeiro relatório de avaliação nacional do painel brasileiro de mudanças climáticas. Sumário Executivo GT1. PBMC, Rio De Janeiro, Brasil. p.44. Disponível: https://www.researchgate.net/publication/3015 42842_Contribuicao_do_Grupo_de_Trabalho _1_ao_Primeiro_Relatorio_de_Avaliacao_Na cional_do_Painel_Brasileiro_de_Mudancas_C
limaticas_Sumario_Executivo_GT1. acesso: 23/05/2016

Sodré, G.R., Moraes, B.C., Ferreira, D.S., Oliveira, J.V., Souza, E.B., 2015. Teleconecxões oceânicas nos padrões climáticos da Amazônia oriental: análises dos últimos 40 anos (19742013). Revista Brasileira de Climatologia. Disponível;

http://dx.doi.org/10.5380/abclima.v17i0.38113 . Acesso:23/07/2018.

Souza, S. P. F., De Souza, E. B., Queiroz, J. C. B., Junior, J. D. A. S. 2017. Impactos dos anos climáticos extremos no rendimento da lavoura temporária de mandioca na região rural da metrópole de belém-pará. Revista Brasileira de Climatologia [online]. Disponível: http://dx.doi.org/10.5380/abclima.v21i0.51459 . Acesso:23/07/2018.

Torres, R. R; Lapola, D. M.; Marengo, J. A.; Lombardo, M. A., 2012. Socio- Climatic Hotspots in Brazil. Climatic Change 115, 597609.

Van Vuuren, D. P.; Edmonds, J.; Kainuma, M.; Riahi, K.; Thomson, A.; Hibbard, K.;.. Rose, S. K., 2011. The Representative Concentration Pathways: an overview. Climatic Change109, 1, 5-310.

Yin, L; Fu, R; Shevliakova, E; Dickinson, R. E. 2013.How well can CMIP5 simulate precipitation and its controlling processes over tropical South America?. Climate Dynamics 41, 3127-3143.

Zeidemann, V., Almeida, O., Rivero, S., \& Thomas, S. 2015. Mudanças climáticas no estuário Amazônico. NAEA/UFPA [online]. Disponível: http://hdl.handle.net/10625/56941. Acesso: 23/07/2018. 